\title{
Retraction note: Grain Refinement of AA5754 Aluminum Alloy by Ultrasonic Cavitation: Experimental Study and Numerical Simulation
}

\author{
R. Haghayeghi, E. Ezzatneshan, and H. Bahai \\ Retraction note: Met. Mater. Int., Vol. 21, No. 1, pp. 109-117 (2015) \\ DOI: 10.1007/s12540-014-6015-5
}

This article has been retracted at the request of the editorial board of Metals and Materials International. The article was examined following the COPE guidelines with regard to suspected plagiarism in a published manuscript.

The article contains figures reproduced from a previously published article with no acknowledgement of the source.

Fig. 3 has been published previously in:

An investigation on physical and chemical refinement of aerospace aluminium alloys

R. Haghayeghi, P. Kapranos

Mater. Lett. 95 (2013) 121-124

The microstructures in Fig. 3 are reproduced from Fig. 3 (a), (b), (c), while being assigned to different alloys and conditions.

The corresponding author R. Haghayeghi submitted the article without the consent of the two co-authors E. Ezzatneshan and H. Bahai. The co-authors also indicate that they did not have knowledge on the previously published data contributed by R. Haghayeghi.

The online version of the original article can be found under doi: 10.1007/s12540-014-6015-5

R. Haghayeghi*, E. Ezzatneshan, and H. Bahai

Department of Materials Engineering, Science and Research Branch, Islamic Azad University, Tehran, Iran e-mail: rhaghayeghi@gmail.com

(C)KIM and Springer 